\title{
Cytogenomic array detects a subset of myelodysplastic syndrome with increased risk that is invisible to conventional karyotype
}

\author{
Sarah M. Choi ${ }^{1}$ (1) | Steven B. Van Norman ${ }^{1}$ | Dale L. Bixby ${ }^{2}$ | Lina Shao ${ }^{1}$
}

${ }^{1}$ Department of Pathology, University of Michigan, Ann Arbor, Michigan

${ }^{2}$ Department of Internal Medicine, University of Michigan, Ann Arbor, Michigan

\section{Correspondence}

Lina Shao, Department of Pathology, University of Michigan, 2800 Plymouth Road, Building 36, Room 1361-2, Ann Arbor, MI 48109-2800.

Email: linashao@med.umich.edu

\begin{abstract}
Conventional karyotyping is essential standard practice in the initial evaluation of myelodysplastic syndrome (MDS) and is the most impactful single component of the Revised International Prognostic Scoring System (IPSS-R). While single nucleotide polymorphism array (SNP-A) has demonstrated the ability to detect chromosomal defects with greater sensitivity than conventional karyotype, widespread adoption is limited by the unknown additional prognostic impact of SNP-A analysis. Here, we investigate the significance of additional SNP-A abnormalities in the setting of MDS and demonstrate differences in survival of patients with additional abnormalities, even those initially characterized as relatively lower risk either by cytogenetic score or IPSS-R. Our findings identify specific abnormalities, particularly KMT2A partial tandem duplication, that are invisible to conventional karyotype and potentially contribute to the poor prognosis of MDS patients. Furthermore, these results demonstrate the added value of SNP-A analysis in identifying patients who may benefit from more aggressive therapy, particularly those who would otherwise be classified into lower risk categories.
\end{abstract}

KEYWORDS

cytogenomic array, MDS, myelodysplastic syndrome, SNP array, SNP-A

\section{1 | INTRODUCTION}

Prognostic classification of myelodysplastic syndrome (MDS) relies heavily on cytogenetic abnormalities and is currently utilized to guide therapeutic decision making, including identifying appropriate candidates for bone marrow transplantation. Indeed, cytogenetic risk is the most heavily weighted component of the Revised International Prognostic Scoring System (IPSS-R), which categorizes patients into multiple risk groups of ascending associated poor prognosis. ${ }^{1}$ While conventional karyotype is the gold standard for detection of genomic abnormalities in both diagnostic and prognostic

Sarah M. Choi and Steven B. Van Norman contributed equally to this study. settings, single nucleotide polymorphism arrays (SNP-As) have emerged as potential means of further categorizing prognostic risk beyond traditional karyotyping in many hematologic malignancies due to the assay's greater sensitivity in detecting unbalanced chromosomal defects and copy-neutral loss of heterozygosity ( $\mathrm{CN}$ $\mathrm{LOH}){ }^{2-6}$ However, widespread adoption and incorporation into prognostic algorithms has not yet occurred despite evidence of the clinical significance of SNP-A in combination with already established karyotypic features. ${ }^{5-8}$ We therefore sought to refine our understanding of the significance of additional SNP-A abnormalities and their impact on prognosis and ultimately risk of death. In particular, given the high frequency of MDS cases showing a normal karyotype, ${ }^{9,10}$ we were especially interested in the potential impact of SNP-A in this group of patients. 


\section{MATERIALS AND METHODS}

This study was approved by the Institutional Review Board of the University of Michigan. We retrospectively reviewed 108 consecutive patients who underwent karyotyping and Thermo Fisher Cytoscan ${ }^{\mathrm{TM}}$ array (SNP-A) analysis ${ }^{11}$ for diagnosis/classification of a suspected myeloid neoplasm and identified 77 patients with a diagnosis of de novo MDS, excluding therapy-related cases. Among these, we identified cases for which additional abnormalities were detected by SNP-A analysis that were not identified using conventional karyotype. We reviewed each patient's electronic medical record including laboratory values at diagnosis (hemoglobin, absolute neutrophil count [ANC], platelet count, and bone marrow blast percentage). We then compared overall survival (OS) based on the presence or absence of additional cytogenomic abnormalities detected by SNP-A on groups that were stratified by cytogenetic risk and IPSS-R score (Figure 1). OS was calculated from date of diagnosis to date of death, censoring for patients alive at the completion of the study. Patients with both lowrisk karyotype (very good-intermediate cytogenetic risk group) and consistent SNP-A results were compared to patients with similar lowrisk karyotype but with additional SNP-A abnormalities. These groups were also stratified by the IPSS-R, and survival was compared in patients with and without additional SNP-A abnormalities. Unpaired $t$, Mann-Whitney, Chi-Square, and Fisher's tests were used as applicable to compare differences in characteristics between groups with and without additional abnormalities. Log-rank (Mantle-Cox) test was used to compare OS between the groups.

\section{3 | RESULTS AND DISCUSSION}

Of the 77 patients for whom both karyotype and SNP-A were performed (Table 1), 36 cases had additional abnormalities detected by SNP-A (47\% of all cases; Table 2; Figure 2). Follow-up time ranged from 1.5 to 85 months (Table 1). Deletions were the most common finding (29 instances), followed by CN-LOH (19 instances). The most prevalent single abnormality detected was $K M T 2 A(M L L)$ partial tandem duplication (KMT2A-PTD) (five cases). Additional abnormalities included cryptic deletions involving TET2 (3), RUNX1 (2), and CUX1 (1). SNP-A detected a monosomy 7 in two cases whose conventional cytogenetics showed a normal karyotype after examining adequate number of metaphase cells.

Cases with and without additional SNP-A abnormalities showed similar overall distribution of morphologic categorization and no statistically significant differences in hemoglobin, ANC, platelet count, bone marrow blast percentage, or IPSS-R (Table 1; Figure S1).

Among matched cases with very good-intermediate cytogenetic risk, those that had additional abnormalities detected on SNP-A showed worse OS (median 35.4 months) than those that did not have additional abnormalities (median survival not reached; Figure $3 \mathrm{~A}$; $P=0.010)$. Similar observations were seen when cases were stratified into matching IPSS-R categories, where very low-intermediate risk cases with additional SNP-A abnormalities showed worse OS (median 35.4 months) similar to cases of high-very high risk (median 31.3 months) compared to very low-intermediate risk cases without additional SNP-A abnormalities (median 62.6 months; Figure 3B; $P=0.020$ ).

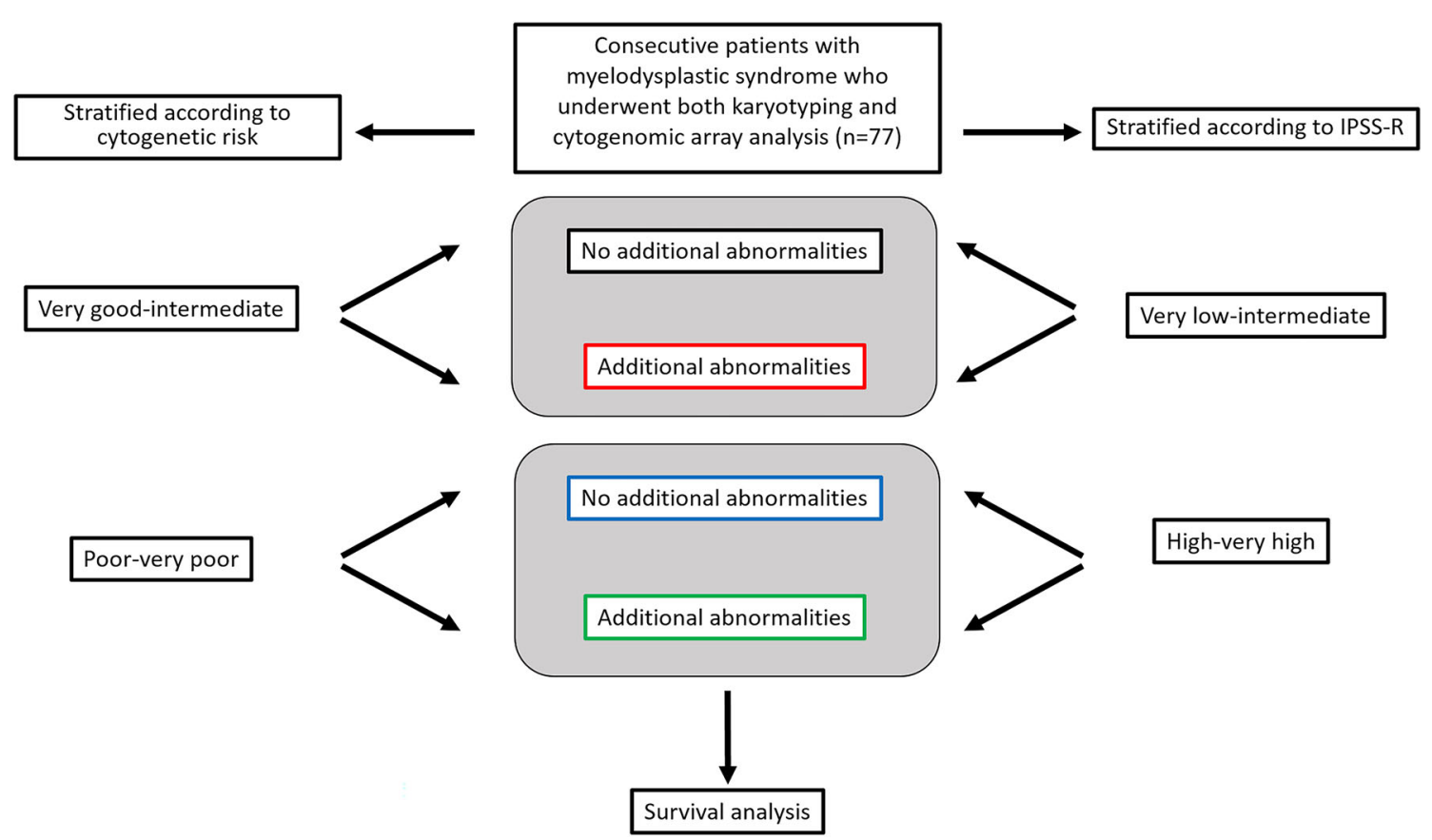

FIGURE 1 Study design. MDS cases for which both karyotyping and cytogenomic array (SNP-A) was performed were stratified by (a) cytogenetic risk and (b) Revised International Prognostic Scoring System (IPSS-R). They were then further stratified based on the presence or absence of additional SNP-A abnormalities. Survival analysis was performed. MDS, myelodysplastic syndrome; SNP-A, single nucleotide polymorphism array [Color figure can be viewed at wileyonlinelibrary.com] 
TAB LE 1 Clinical characteristics of study group

\begin{tabular}{|c|c|c|c|c|c|c|c|}
\hline & \multirow[b]{2}{*}{ Total } & \multicolumn{6}{|c|}{ Cytogenetic risk group } \\
\hline & & $\begin{array}{l}\text { No additional } \\
\text { SNP-A } \\
\text { abnormalities }\end{array}$ & $\begin{array}{l}\text { Additional } \\
\text { SNP-A } \\
\text { abnormalities }\end{array}$ & $P$ & $\begin{array}{l}\text { No additional } \\
\text { SNP-A } \\
\text { abnormalities }\end{array}$ & $\begin{array}{l}\text { Additional } \\
\text { SNP-A } \\
\text { abnormalities }\end{array}$ & $P$ \\
\hline Number of patients & 77 & 33 & 26 & & 8 & 10 & \\
\hline Sex & 77 & & & 0.59 & & & 0.64 \\
\hline Male & 50 & 20 & 18 & & 6 & 6 & \\
\hline Female & 27 & 13 & 8 & & 2 & 4 & \\
\hline Initial diagnosis & 77 & & & 0.29 & & & 0.46 \\
\hline MDS-SLD & 8 & 3 & 4 & & 1 & 0 & \\
\hline IPSS-R & & $3(2.5-4.9)$ & $2.75(1.5-4.25)$ & 0.16 & $6(4.25-7.6)$ & $7.25(6-8.5)$ & 0.14 \\
\hline $\mathrm{ANC}, \mathrm{k} / \mu \mathrm{L}$ & & $1.6(0.8-3.4)$ & $1.7(1.0-2.5)$ & 0.79 & $0.9(0.3-2.3)$ & $0.8(0.5-1.4)$ & 0.85 \\
\hline $\mathrm{Hgb}, \mathrm{g} / \mathrm{dL}$ & & $9.8(8.1-11.5)$ & $9.6(8.0-10.9)$ & 0.73 & $9.0(7.6-9.9)$ & $9.1(8.0-9.5)$ & 0.56 \\
\hline $\mathrm{Plt}, \mathrm{k} / \mu \mathrm{L}$ & & $75.5(53-191)$ & $118(66-180)$ & 0.6 & $65(30-110)$ & $43(18-59)$ & 0.37 \\
\hline BM blast percent, $\%$ & & $2.3(0.9-6.1)$ & $2.0(1.0-4.3)$ & 0.95 & $1.8(0.3-6.7)$ & $3.4(1.3-9.8)$ & 0.24 \\
\hline Therapy & & & & 0.8 & & & NA \\
\hline Supportive & & 15 & 12 & & 2 & 4 & \\
\hline Hypomethylating agent & & 18 & 12 & & 5 & 7 & \\
\hline Number of patients & 77 & 26 & 20 & & 18 & 13 & \\
\hline Age & & $67.9(59.7-75.0)$ & $74.0(62.8-79.8)$ & 0.22 & $62.5(59.5-71.4)$ & $69.1(65.4-76.3)$ & 0.14 \\
\hline Sex & 77 & & & 0.35 & & & $>0.99$ \\
\hline Male & 50 & 15 & 15 & & 12 & 8 & \\
\hline Female & 27 & 11 & 5 & & 6 & 5 & \\
\hline Initial diagnosis & 77 & & & 0.16 & & & 0.69 \\
\hline MDS-SLD & 8 & 5 & 3 & & 0 & 0 & \\
\hline MDS-MLD & 35 & 16 & 11 & & 4 & 4 & \\
\hline MDS-EB1 & 12 & 4 & 1 & & 5 & 2 & \\
\hline MDS-EB2 & 22 & 1 & 5 & & 9 & 7 & \\
\hline IPSS-R & & $2.75(2-3.5)$ & $2(1.5-3)$ & 0.3 & $6(5.5-6.5)$ & $6.25(5.6-7.9)$ & 0.3 \\
\hline $\mathrm{ANC}, \mathrm{k} / \mu \mathrm{L}$ & & $1.6(0.8-3.3)$ & $2(1.1-2.6)$ & 0.37 & $1.2(0.4-3.1)$ & $0.9(0.5-1.9)$ & 0.83 \\
\hline $\mathrm{Hgb}, \mathrm{g} / \mathrm{dL}$ & & $10.1(8.6-12.3)$ & 10.1 (8.1-11.3) & 0.66 & $8.3(7.5-9.8)$ & $9.0(7.6-9.4)$ & 0.86 \\
\hline $\mathrm{Plt}, \mathrm{k} / \mu \mathrm{L}$ & & $87.5(69.5-164)$ & $118(69.8-189)$ & 0.62 & $44(28-81)$ & $45(24-122)$ & 0.98 \\
\hline BM blast percent, \% & & $1.6(0.6-2.5)$ & $1.9(0.8-2.1)$ & 0.77 & $8(1.5-10)$ & $7.4(2.1-12)$ & 0.58 \\
\hline
\end{tabular}


TABLE 1 (Continued)

\begin{tabular}{|c|c|c|c|c|c|c|}
\hline & \multicolumn{6}{|l|}{ IPSS-R } \\
\hline & \multicolumn{2}{|c|}{ Very low-intermediate risk } & & \multicolumn{2}{|l|}{ High-very high } & \multirow[b]{2}{*}{$P$} \\
\hline & $\begin{array}{l}\text { No additional } \\
\text { SNP-A } \\
\text { abnormalities }\end{array}$ & $\begin{array}{l}\text { Additional } \\
\text { SNP-A } \\
\text { abnormalities }\end{array}$ & $P$ & $\begin{array}{l}\text { No additional } \\
\text { SNP-A } \\
\text { abnormalities }\end{array}$ & $\begin{array}{l}\text { Additional } \\
\text { SNP-A } \\
\text { abnormalities }\end{array}$ & \\
\hline Supportive & 14 & 10 & & 3 & 6 & \\
\hline Hypomethylating agent & 13 & 9 & & 10 & 10 & \\
\hline Transplant & 5 & 3 & & 7 & 2 & \\
\hline Other & 4 & 3 & & 1 & 3 & \\
\hline Median follow up time, months & 46.2 & 26.5 & & 24.2 & 10.3 & \\
\hline
\end{tabular}

Note: Median value (25th-75th percentile) displayed; "Other" therapy (therapies not listed above).

Abbreviations: ANC, absolute neutrophil count; BM, bone marrow; Hgb, hemoglobin; IPSS-R, Revised International Prognostic Scoring System; NA, unable to perform; PIt, platelet count; SNP-A, single nucleotide polymorphism array.

FIGURE 2 Frequency of additional SNP-A abnormalities. The number of instances of each type of additional abnormality, which were not detected by conventional karyotype, is depicted for each chromosome. CN-LOH, copy-neutral loss of heterozygosity; SNP-A, single nucleotide polymorphism array [Color figure can be viewed at wileyonlinelibrary.com]

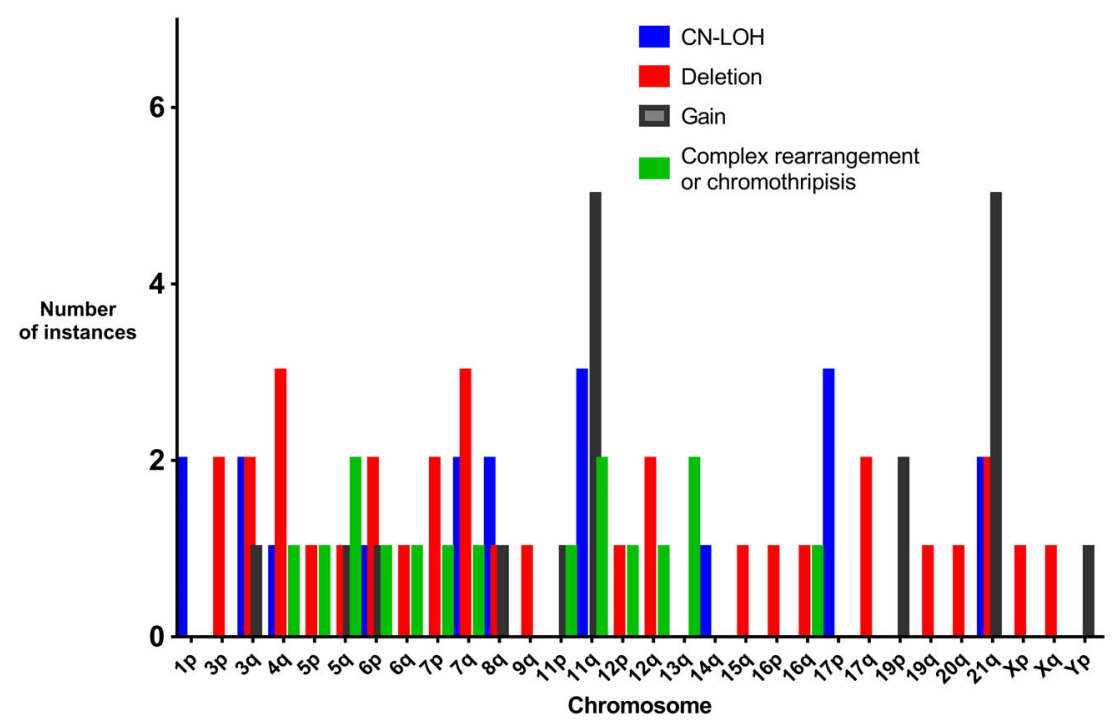

On the contrary, in cases with either poor-very poor cytogenetic risk or high-very high IPSS-R score, the presence of additional SNP-A abnormalities did not show a statistically significant impact on OS though a trend toward poorer survival was observed (Figures 3A, $P=0.054$ and Figures 3B, $P=0.052$ ). This finding suggests that the prognostic impact of SNP-A abnormalities may be primarily concentrated in cases that would otherwise be classified as lower risk either by cytogenetic score or IPPS-R.

We questioned whether or not incorporating additional SNP-A findings would impact the calculated IPSS-R. Taking into consideration cases with anomalies that were greater than $5 \mathrm{Mb}$ excluding CN-LOH and small focal deletions and gains, only two cases changed IPSS-R (one from very low to intermediate; one from very low to low). In terms of our analysis, therefore, there was no impact on survival.

Based on our previous observation of a small cohort of low-risk MDS cases of KMT2A-PTD which showed poor OS, ${ }^{12}$ we questioned whether this single abnormality could be responsible for the survival differences of the cases with additional SNP-A abnormalities. When KMT2A-PTD cases were excluded from the analysis, the effects of additional SNP-A abnormalities when stratifying patients according to cytogenetic risk and IPSS-R were somewhat abrogated. A trend toward poorer survival was still noticeable, but no longer statistically significant (Figure 4A; $P=0.069$ and Figure 4B; $P=0.063$ ). Consequently, KMT2A-PTD may be at least partly responsible for the worse survival seen in patients with additional SNP-A abnormalities and otherwise very good-intermediate cytogenetic risk or very lowintermediate IPSS-R, though other abnormalities may also contribute to a lesser extent. Genomic locations of KMT2A-PTD in five cases are shown in Figure 5.

To summarize, our findings suggest that the presence of additional SNP-A abnormalities, detected in almost half of MDS cases, has further impact on prognosis and OS than that afforded by conventional karyotype analysis. Cases identified as very good-intermediate cytogenetic risk that have additional SNP-A abnormalities demonstrate OS approaching that of patients with poor-very poor cytogenetic risk. Similarly, cases identified as very low-intermediate risk by IPSS-R demonstrate OS more similar to patients with high-very high risk by IPSS-R. Although a significant component of these differences may be 


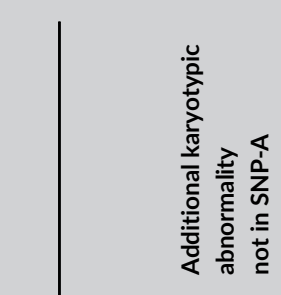

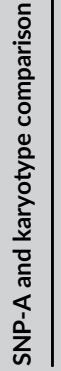
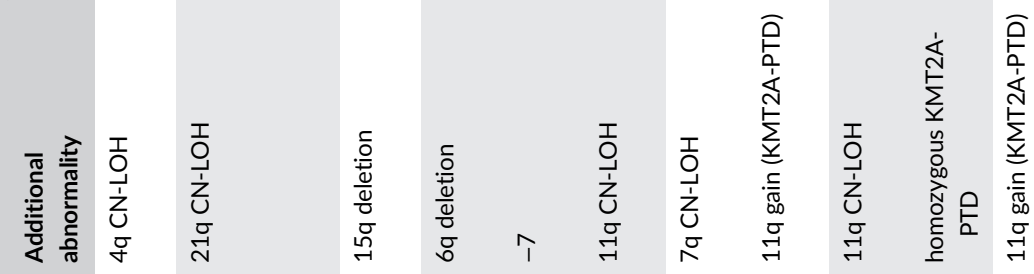

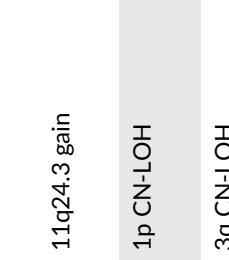
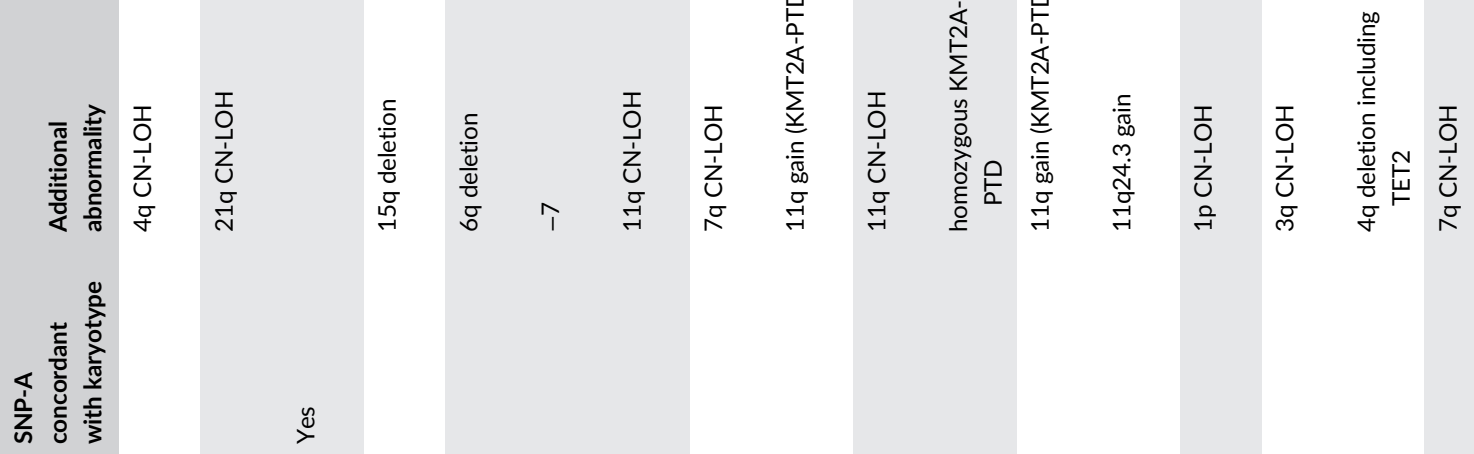

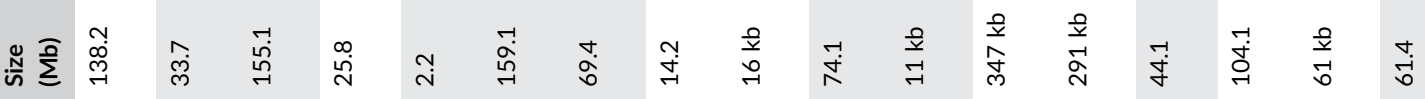
ㅇำ $\begin{aligned} & 8 \\ & 0\end{aligned}$ वे है

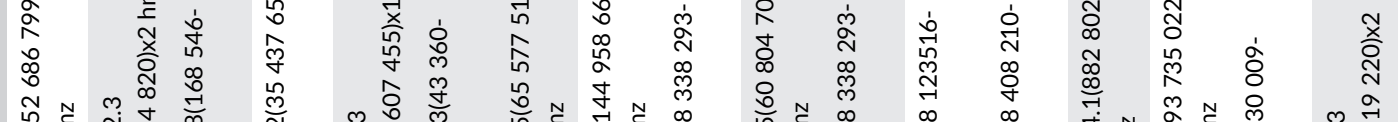

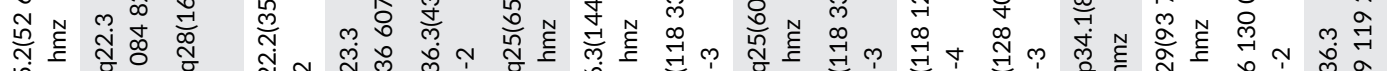

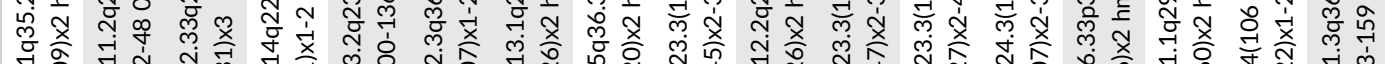

量 y

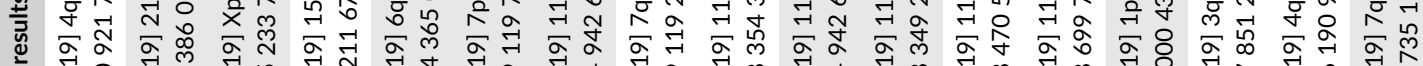

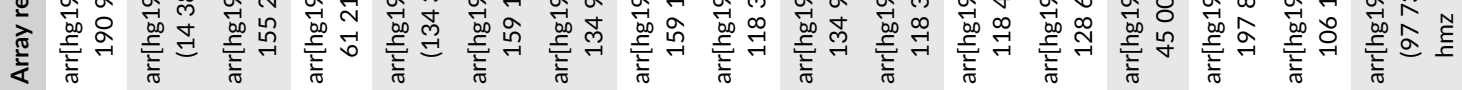

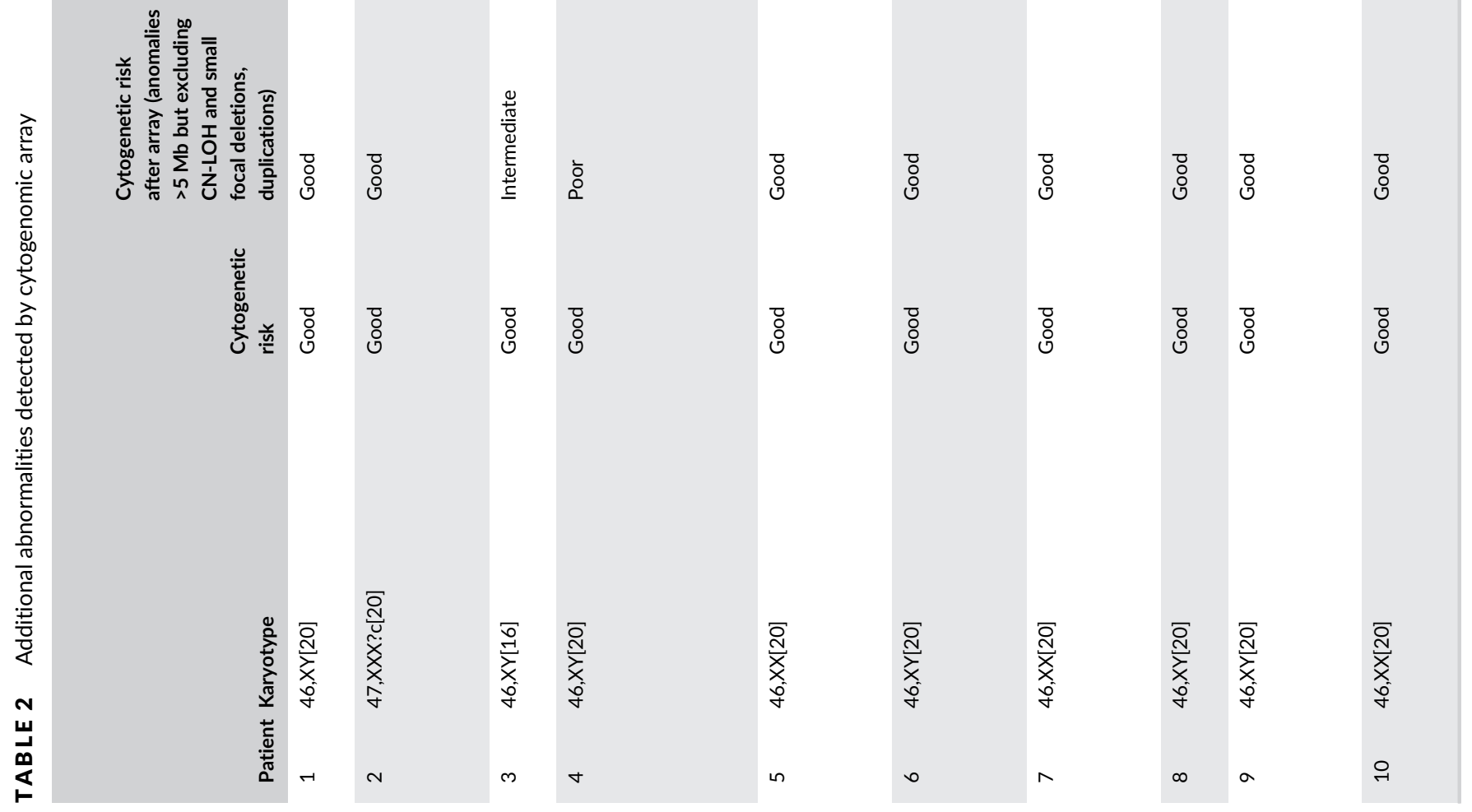




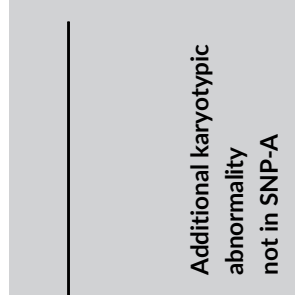

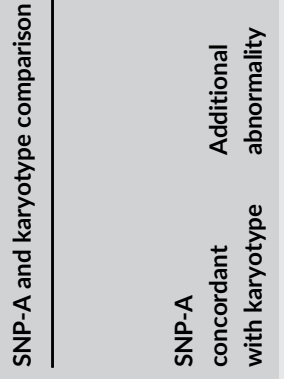

กิำ

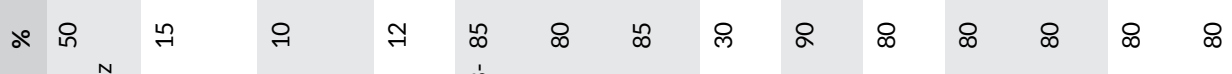

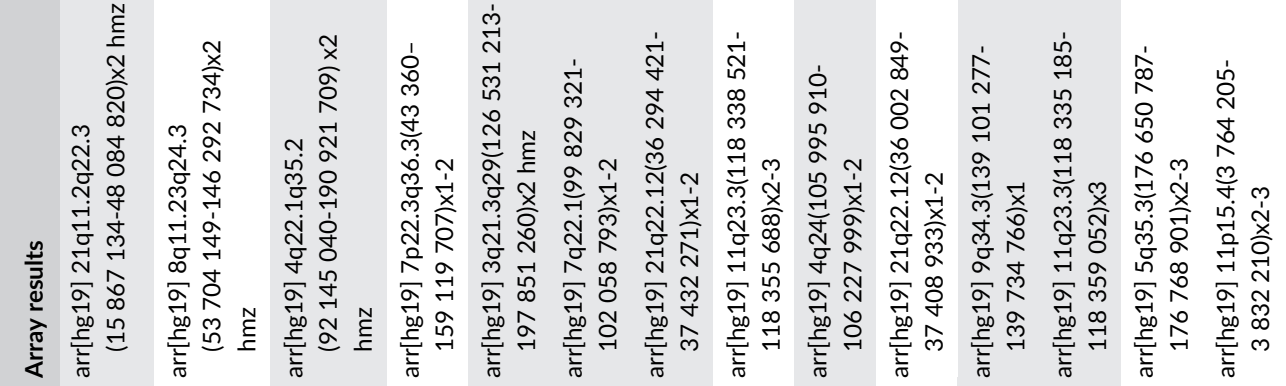

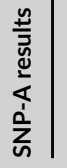

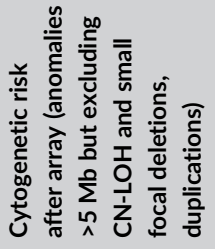

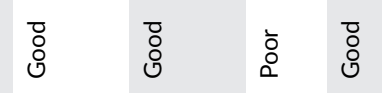

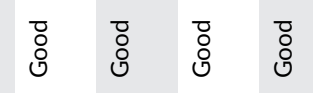

$\bar{s}$

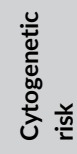

\begin{tabular}{llll}
$\overline{0}$ & $\overline{0}$ & $\overline{0}$ & $\overline{0}$ \\
\hdashline & 0 & $\circ$ & 0 \\
0 & 0 & 0
\end{tabular}

ำำ

马

裹高

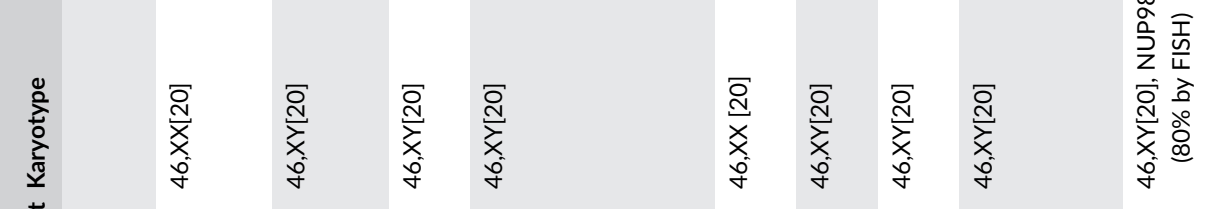

莫

$\exists \quad \stackrel{\rightarrow}{\rightarrow} \stackrel{\rightarrow}{\rightarrow}$

$\stackrel{2}{\rightarrow}$ ำ $\stackrel{\infty}{\sim}$

$\stackrel{9}{\rightarrow}$ 


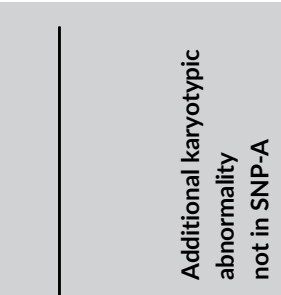

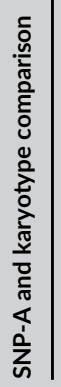
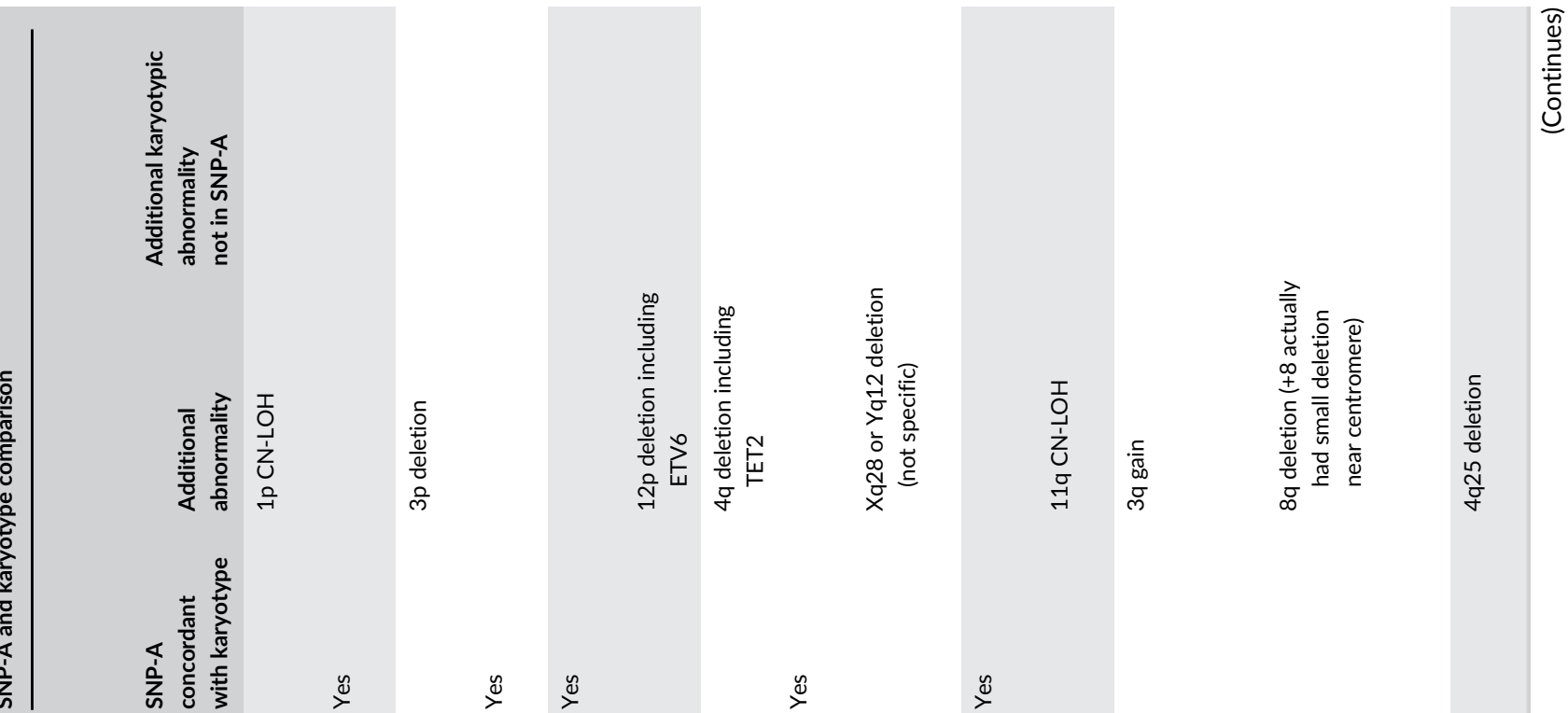

$\stackrel{0}{x}$

$\stackrel{\mathscr{s}}{x}$

$\stackrel{y}{\succ}$

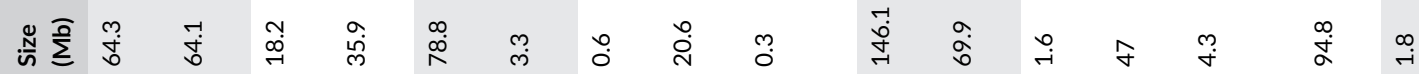

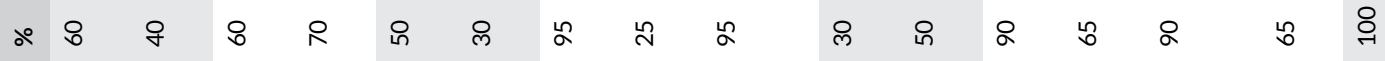

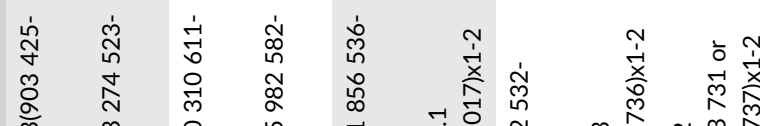

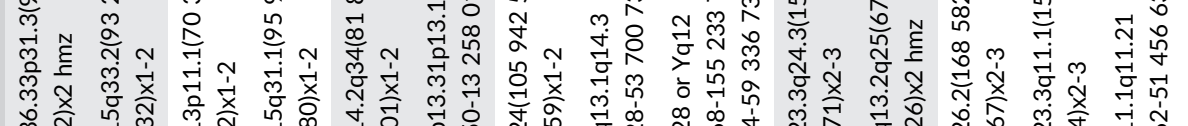

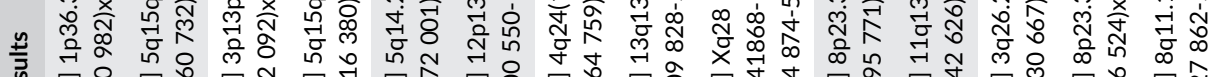

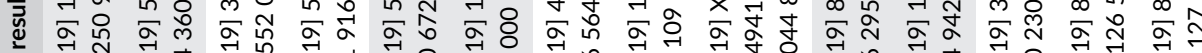

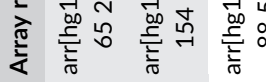

害

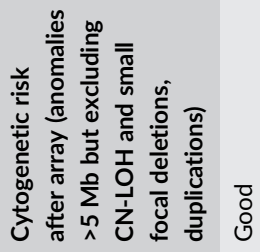

$\frac{8}{8}$
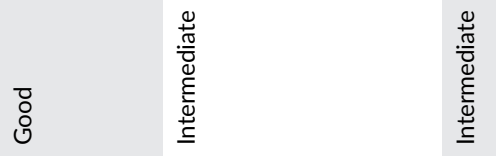

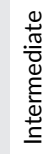

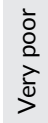
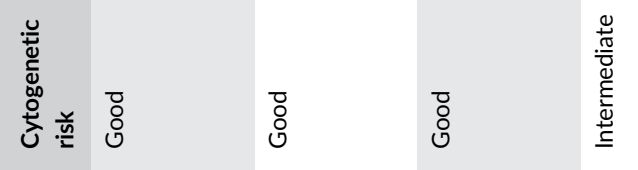

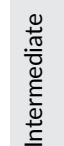

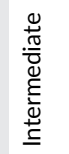

ปั่

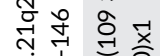

न

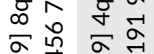

总点 


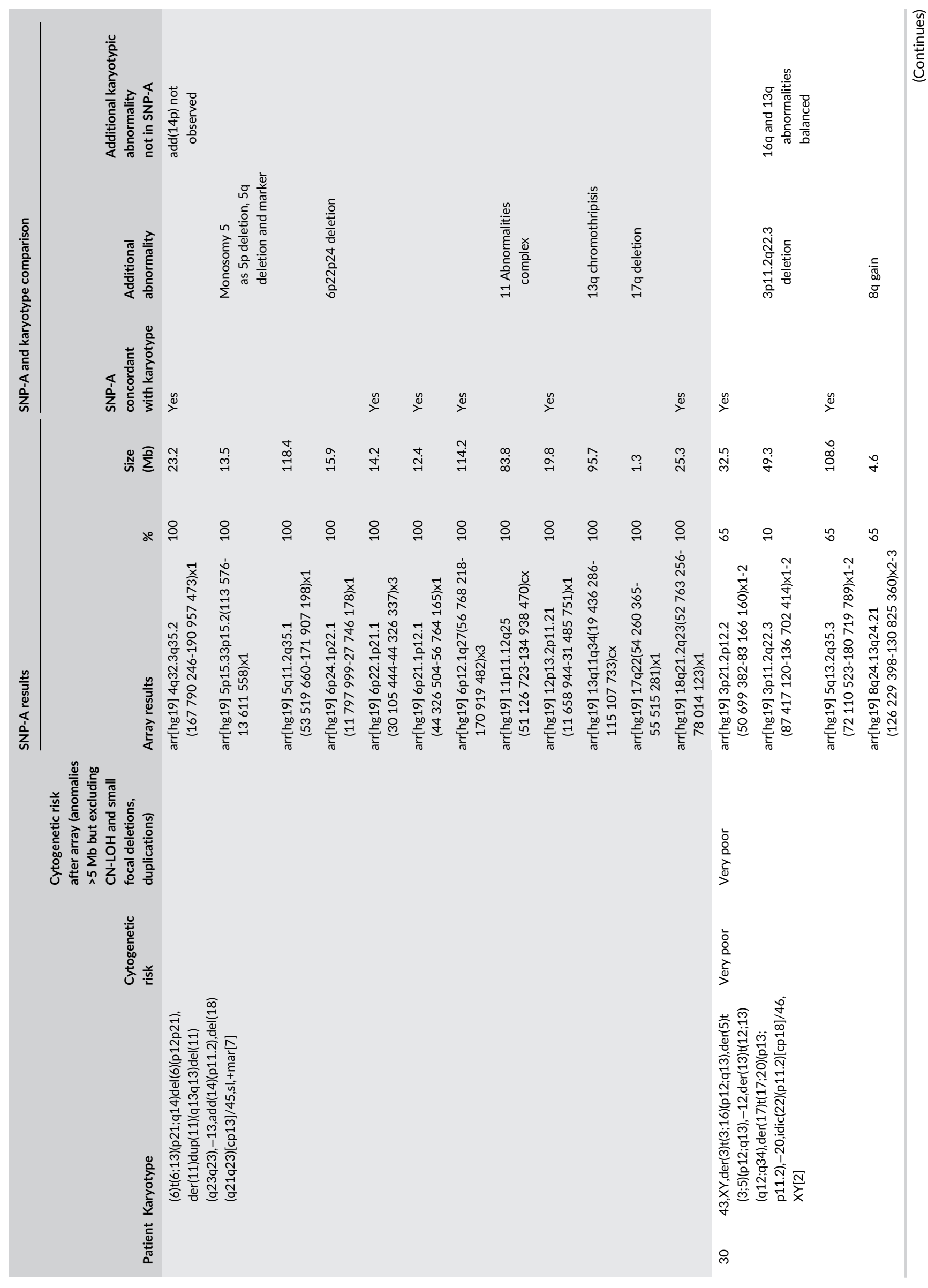



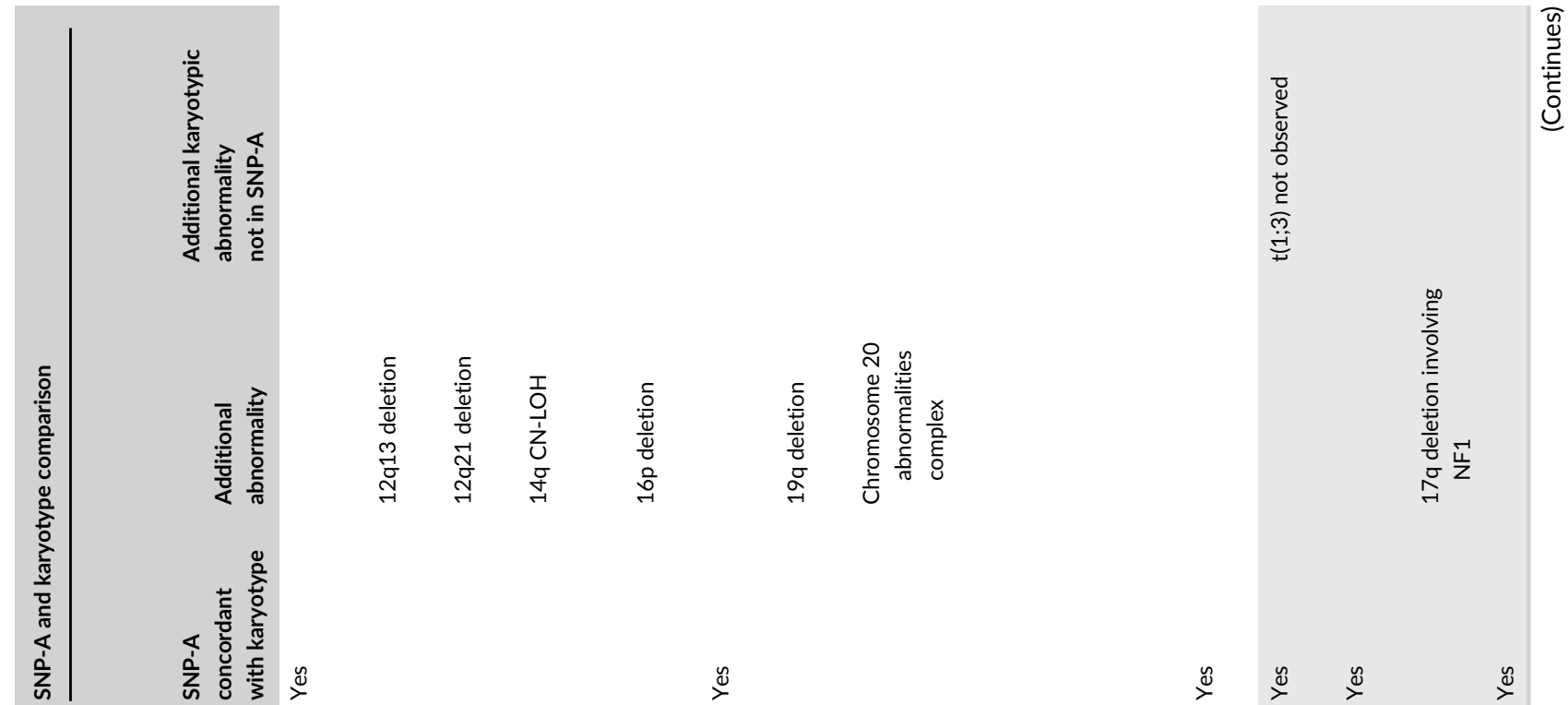

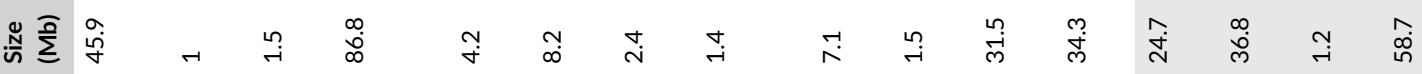

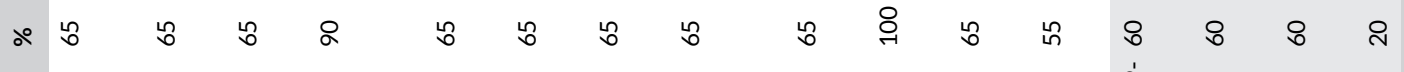

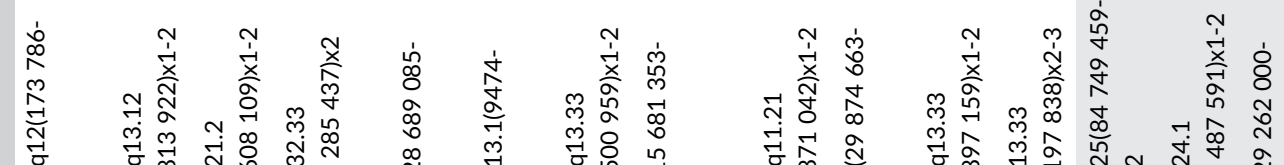

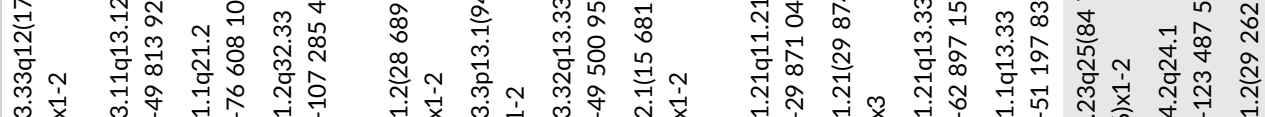

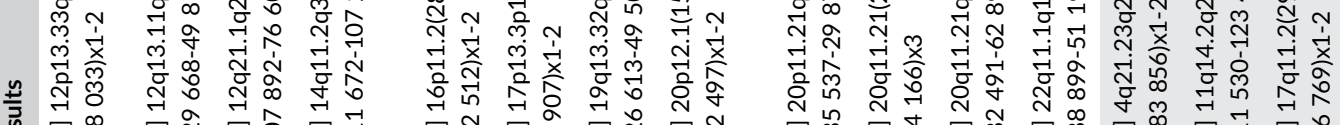

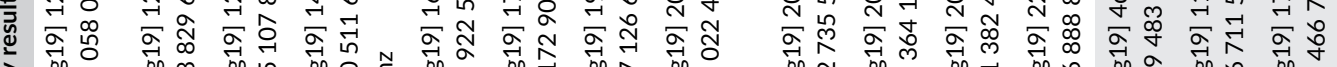

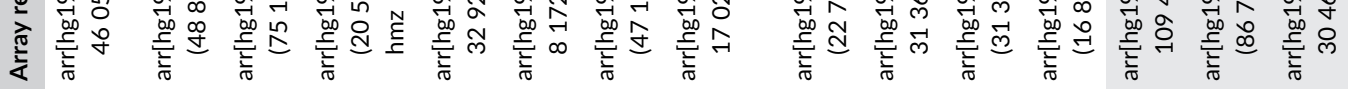

紊

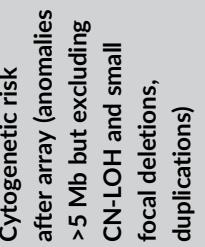

홍

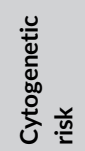

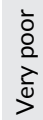
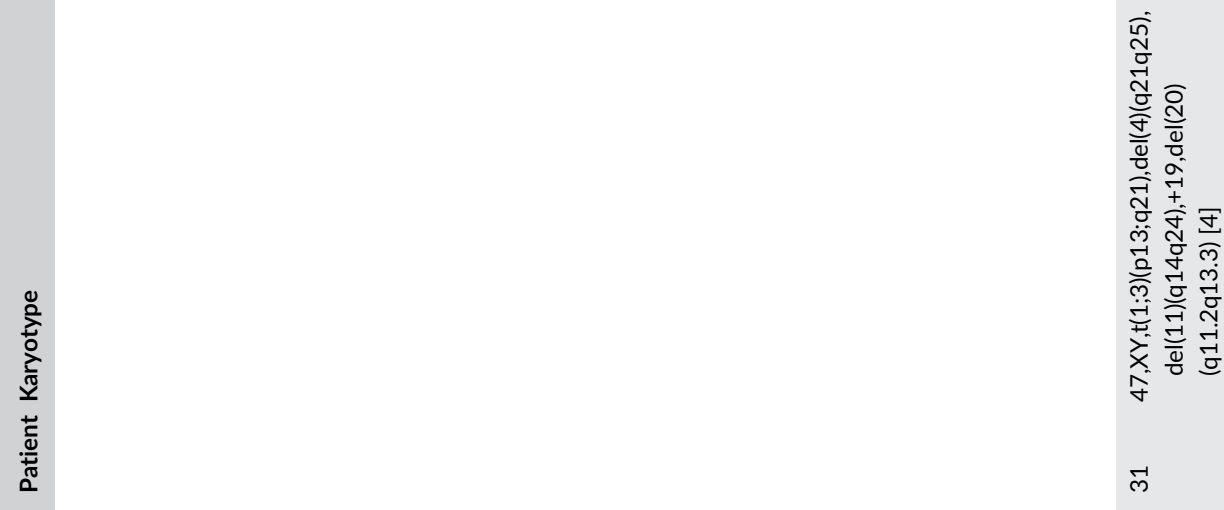

ले 


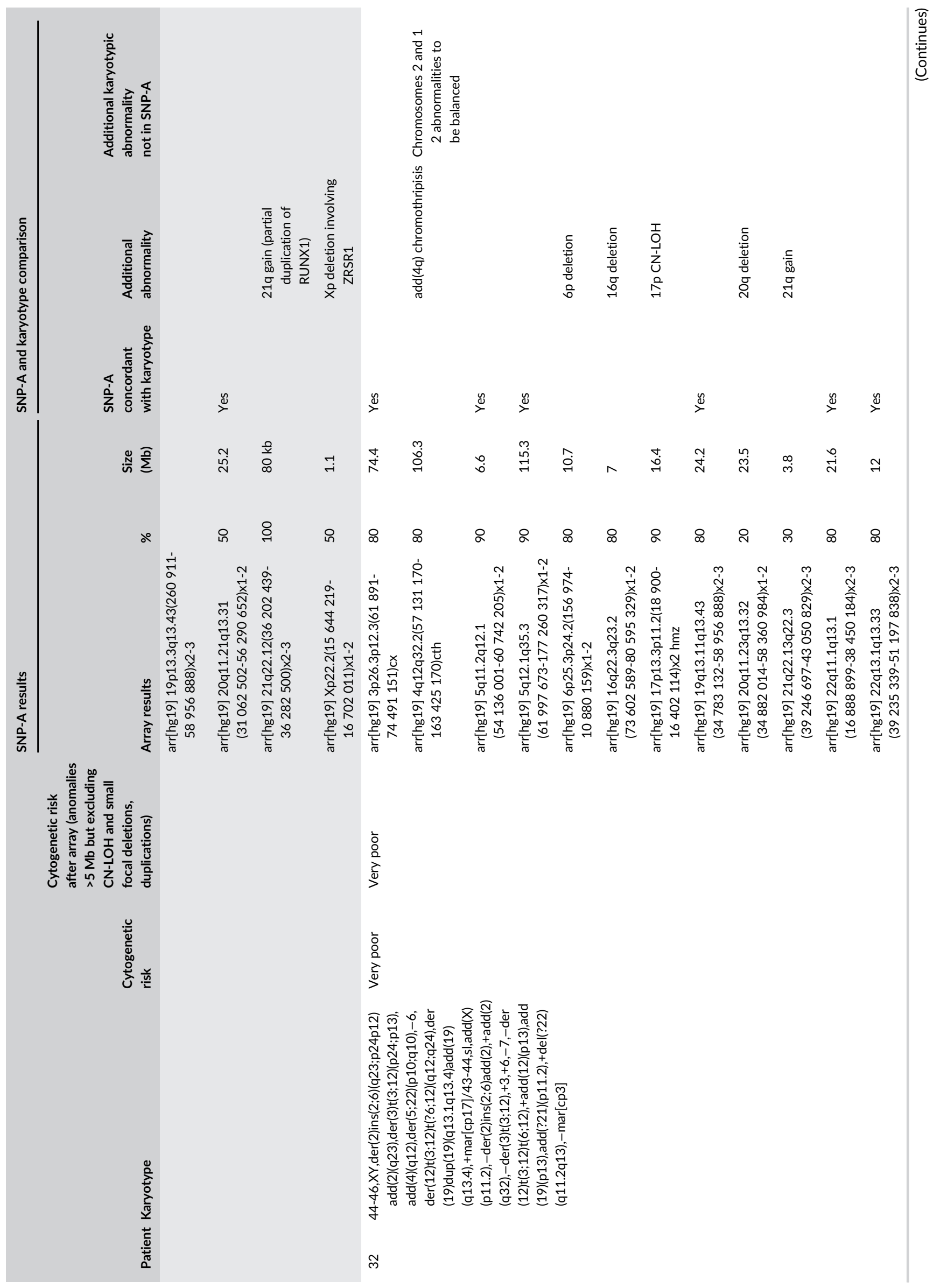




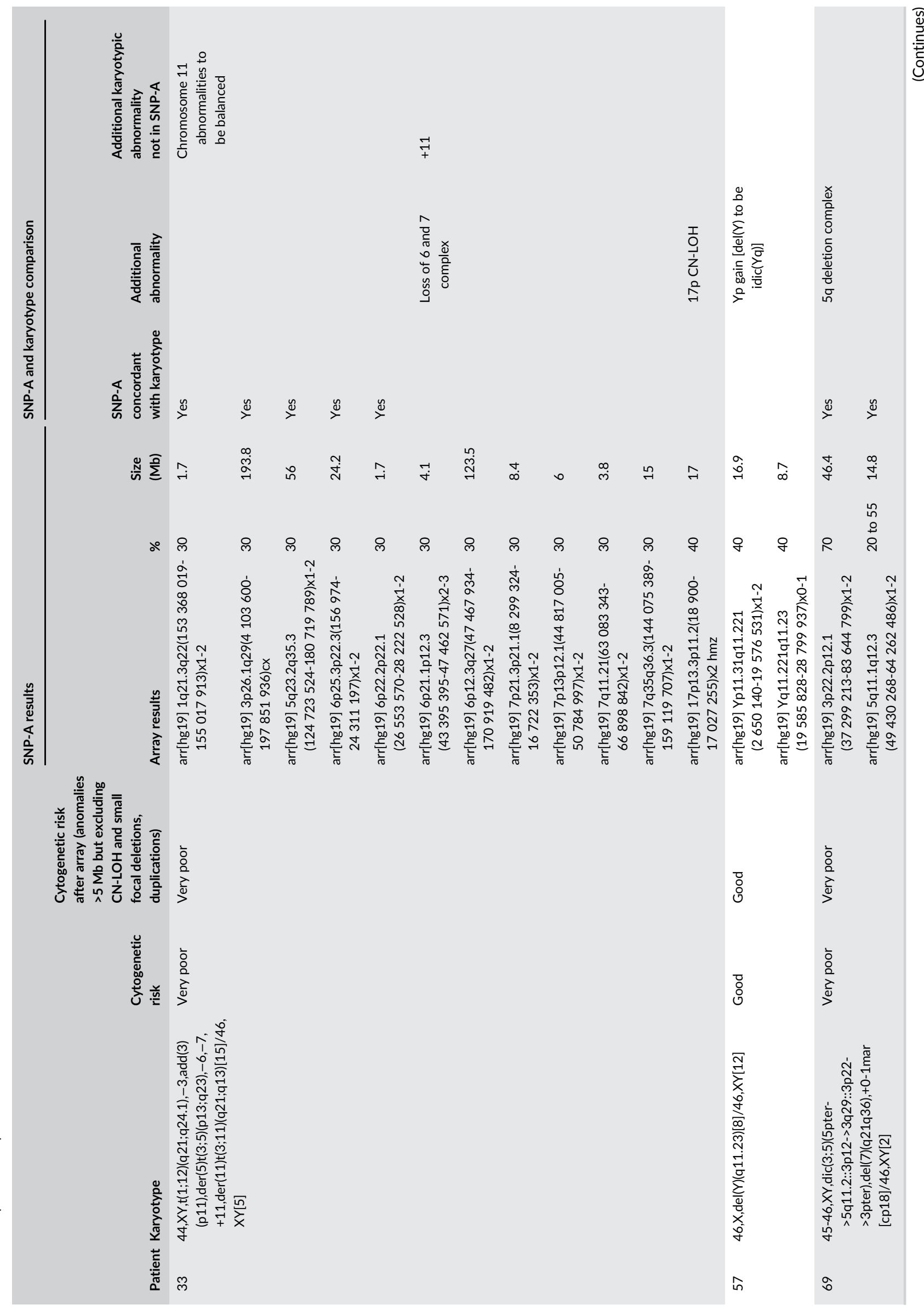




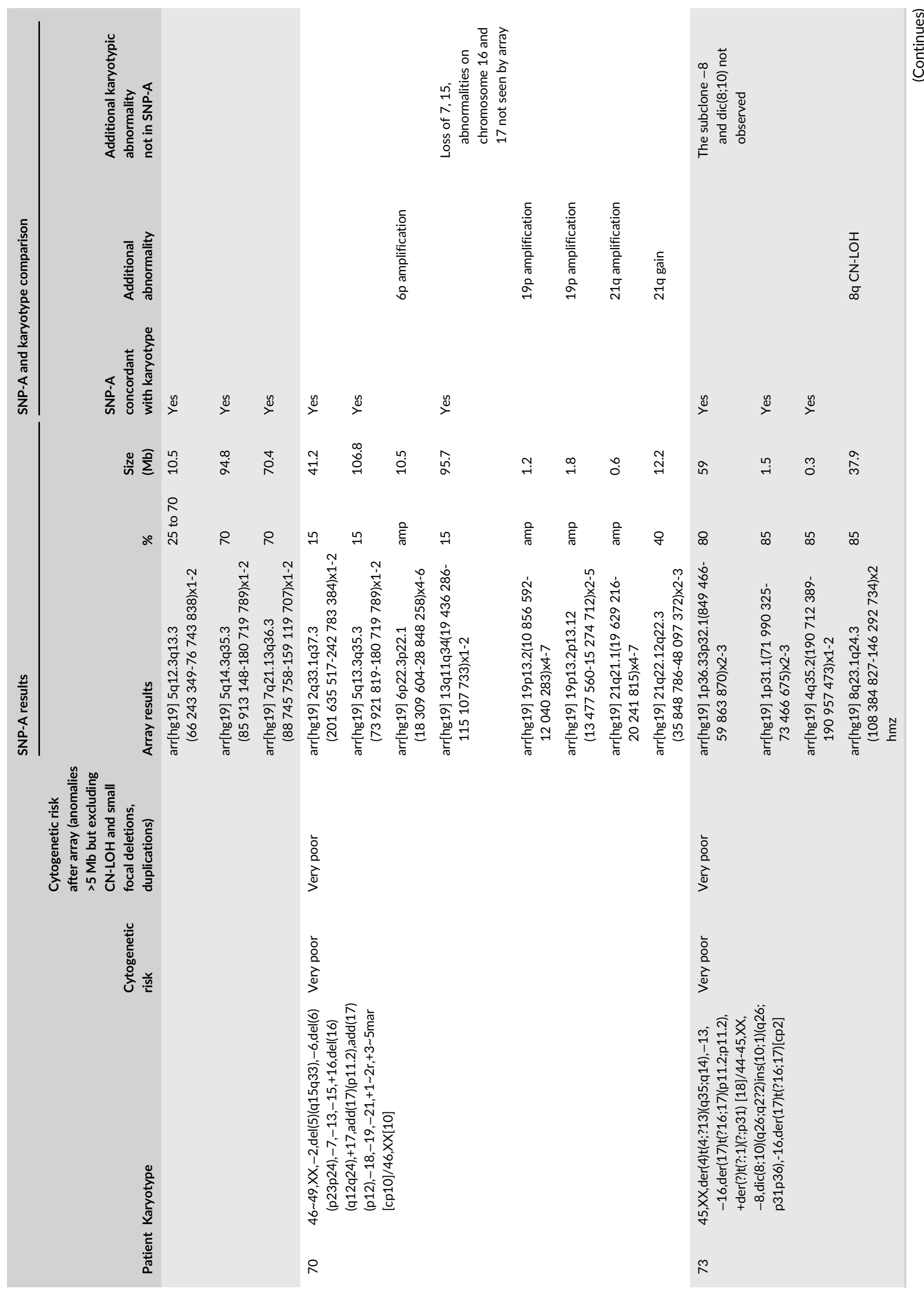



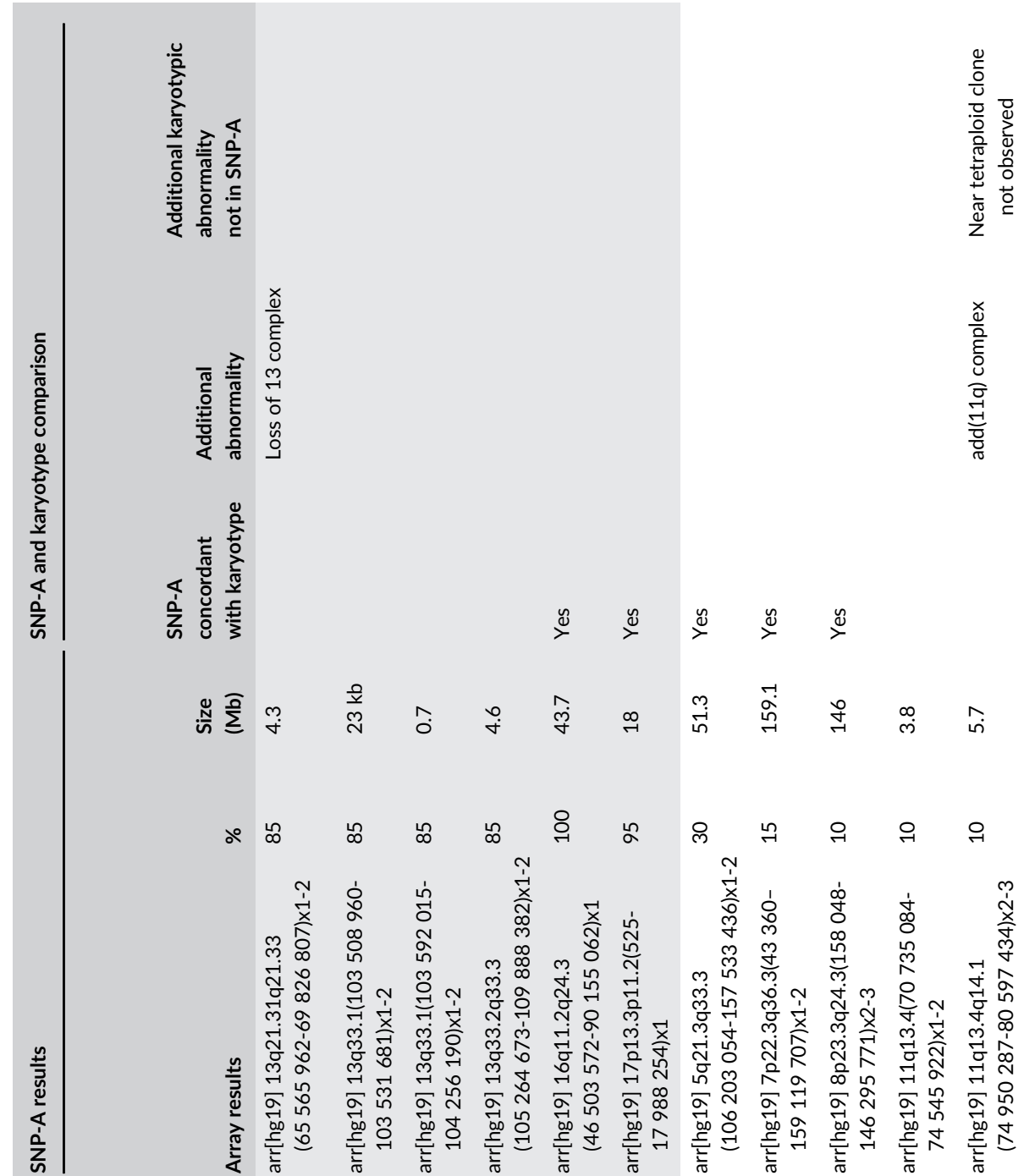

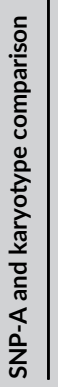

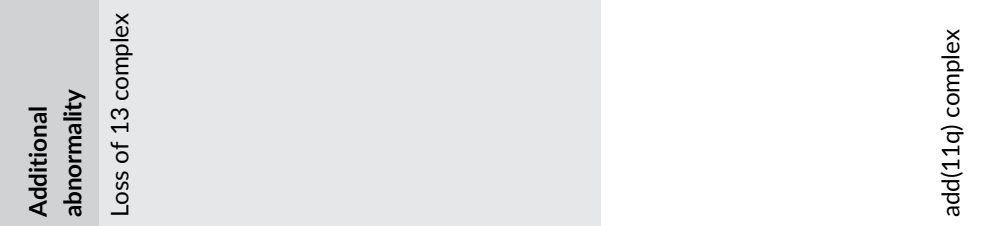

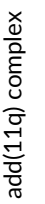

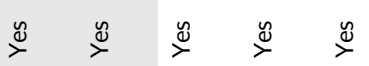

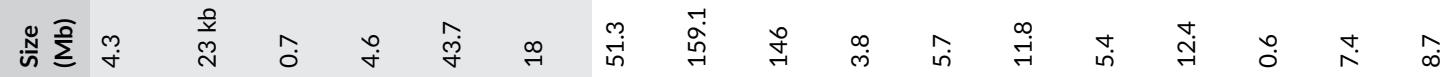

유

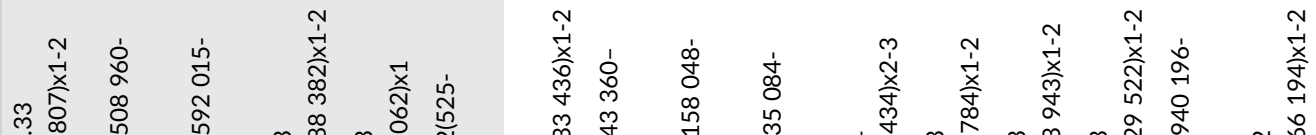

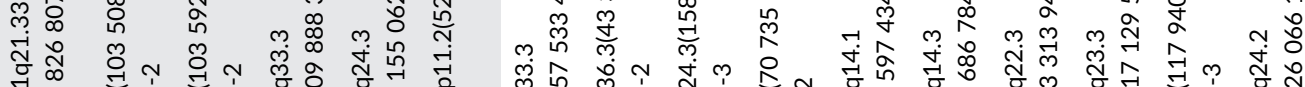
गु n

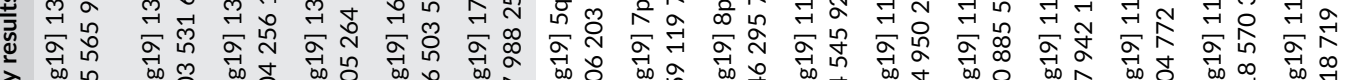

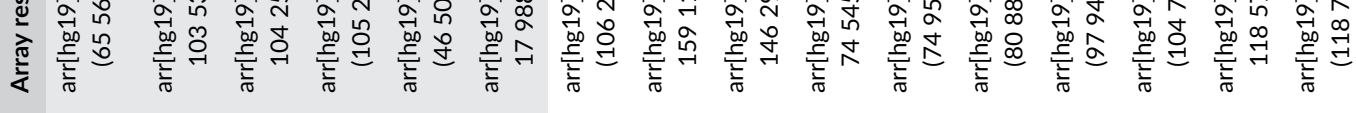

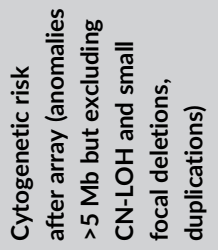

$\frac{\grave{o}}{\stackrel{0}{2}}$

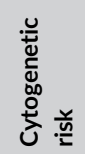

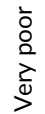

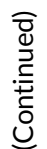

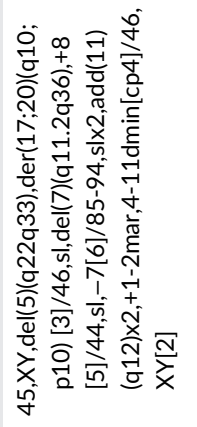




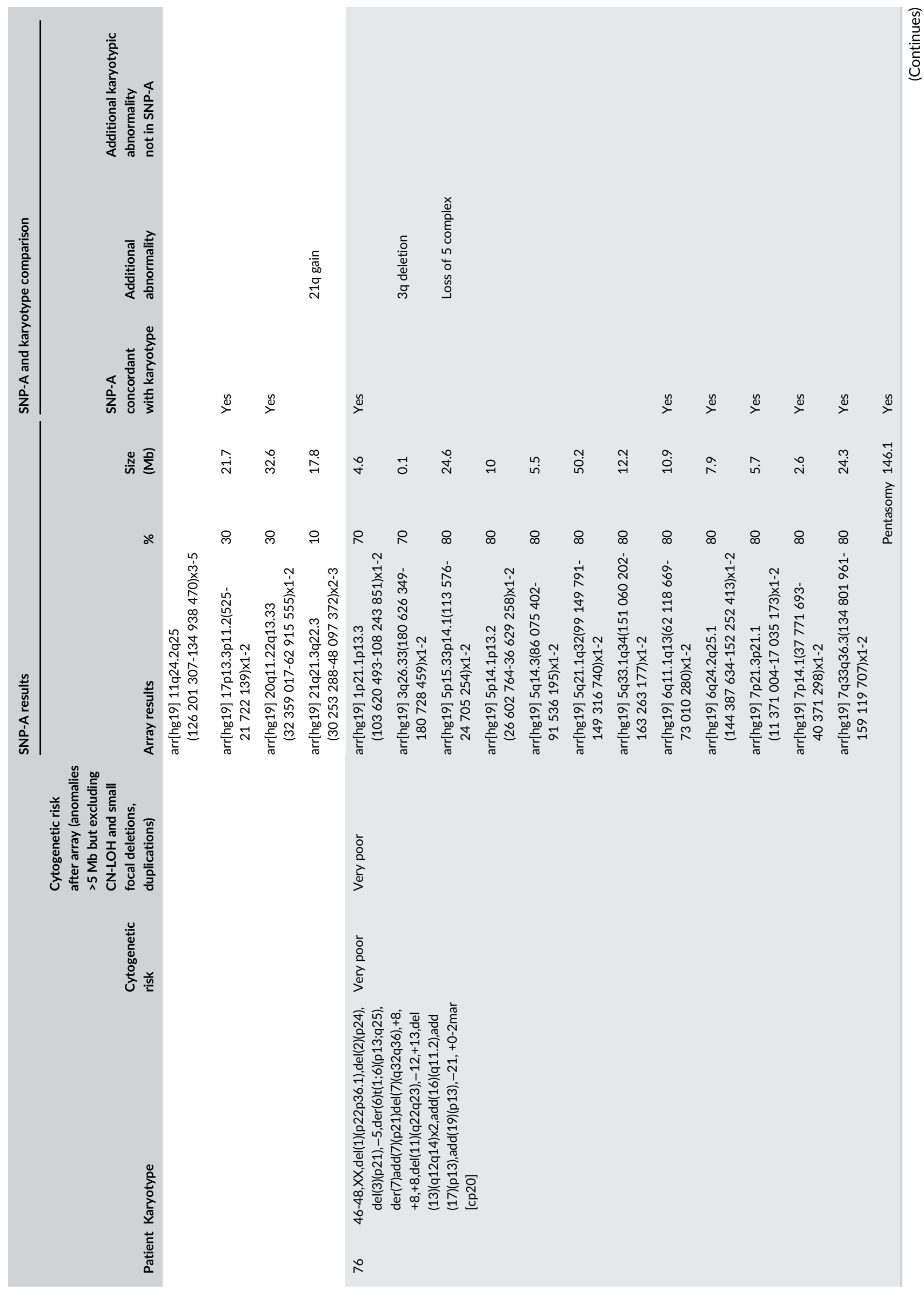



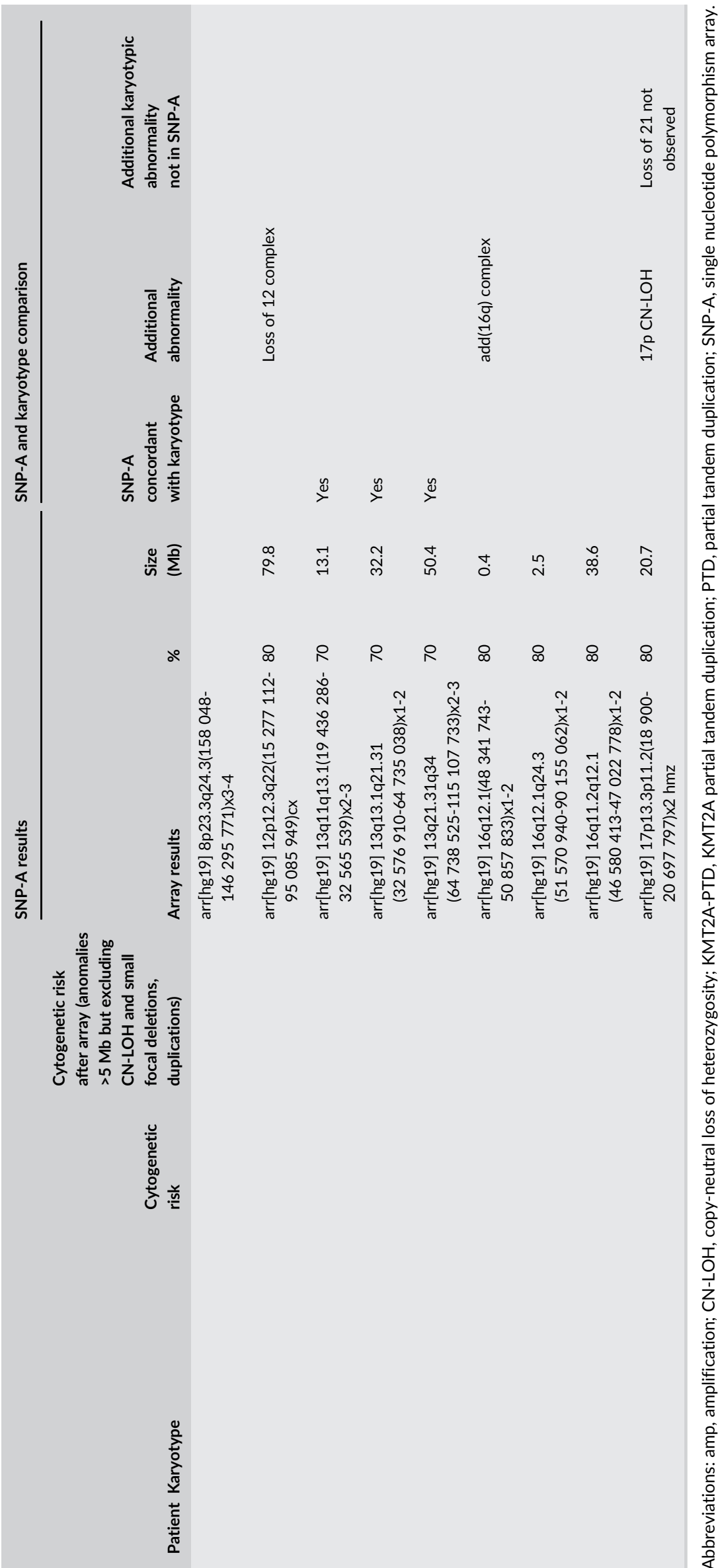

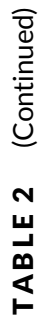

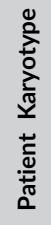


(A) Stratified by cytogenetic risk

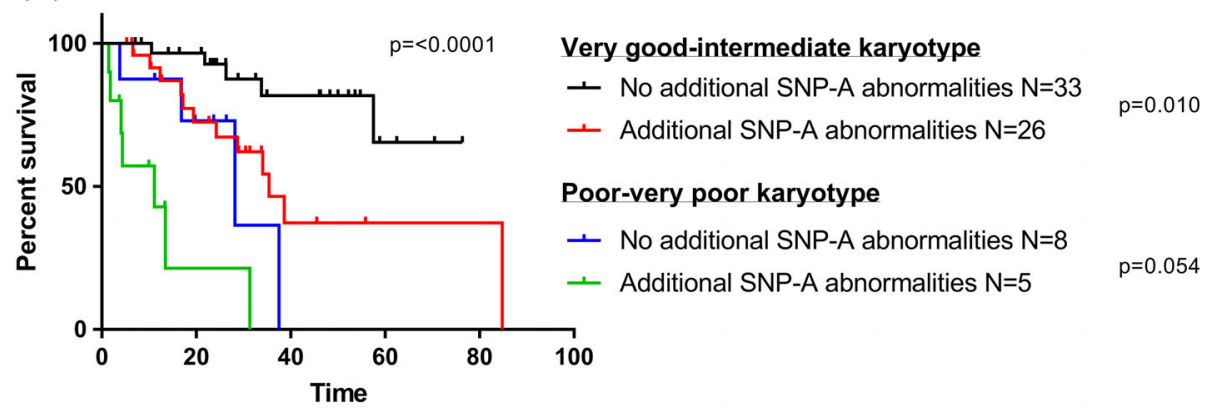

(B) Stratified by IPSS-R

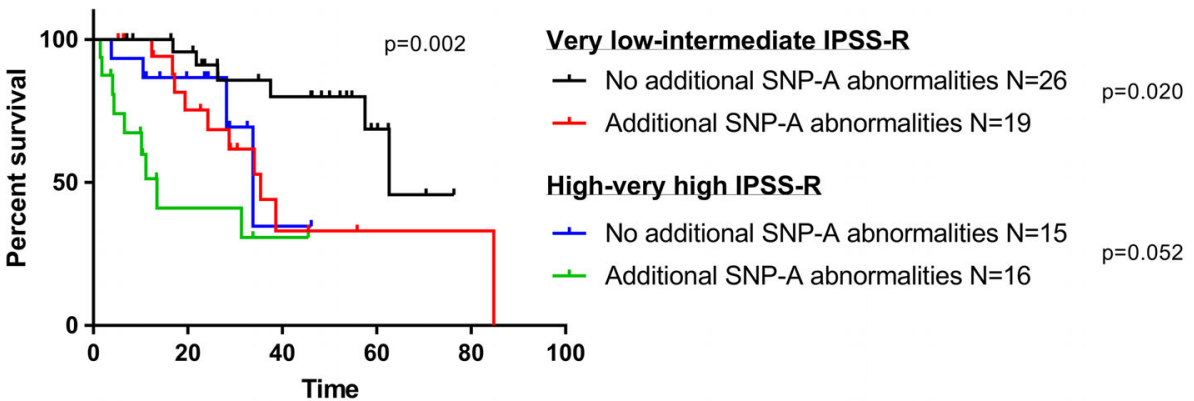

FIGURE 3 The presence of additional SNP-A abnormalities negatively impacts survival in patients with very good-intermediate cytogenetic risk and very low-intermediate IPSS-R. Survival analysis of patients stratified by cytogenetic risk $(A ; P<0.0001)$ and by IPSS-R (B; $P=0.002)$ was performed comparing cases with and without additional SNP-A abnormalities. A, Cases with very good-intermediate cytogenetic risk with additional SNP-A abnormalities showed worse overall survival than those that did not have additional abnormalities $(P=0.010$; black and red groups). SNP-A abnormalities had no statistically significant survival impact in cases with poor-very poor cytogenetic risk ( $P=0.054$; green and blue groups). B, Very low-intermediate IPSS-R cases with additional SNP-A abnormalities showed worse overall survival compared to those without additional abnormalities ( $P=0.020$; black and red groups). SNP-A abnormalities had no statistically significant survival impact in cases with high-very high IPSS-R score ( $P=0.052$; green and blue groups). IPSS-R, Revised International Prognostic Scoring System; SNP-A, single nucleotide polymorphism array [Color figure can be viewed at wileyonlinelibrary.com]
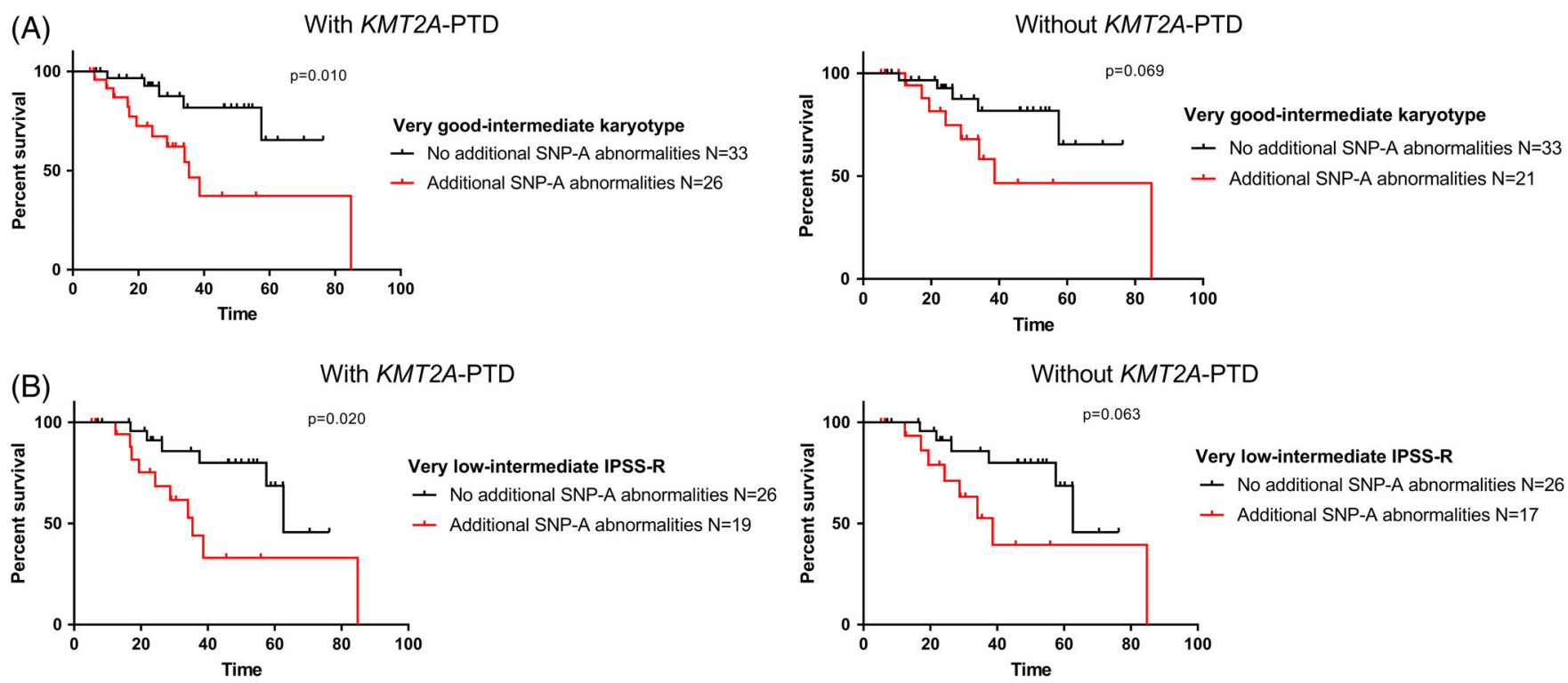

FIG URE 4 KMT2A-PTD significantly impacts survival of patients with additional SNP-A abnormalities. A, Patients with very goodintermediate karyotype showed worse survival in the presence of additional SNP-A abnormalities $(P=0.010)$, an effect which was abrogated but not completely eliminated when cases of KMT2A-PTD were excluded $(P=0.069)$. B, Similar survival effects were seen in cases with very lowintermediate IPSS-R with $(P=0.020)$ and without $(P=0.063)$ KMT2A-PTD. IPSS-R, Revised International Prognostic Scoring System; KMT2APTD, KMT2A partial tandem duplication; SNP-A, single nucleotide polymorphism array [Color figure can be viewed at wileyonlinelibrary.com] 


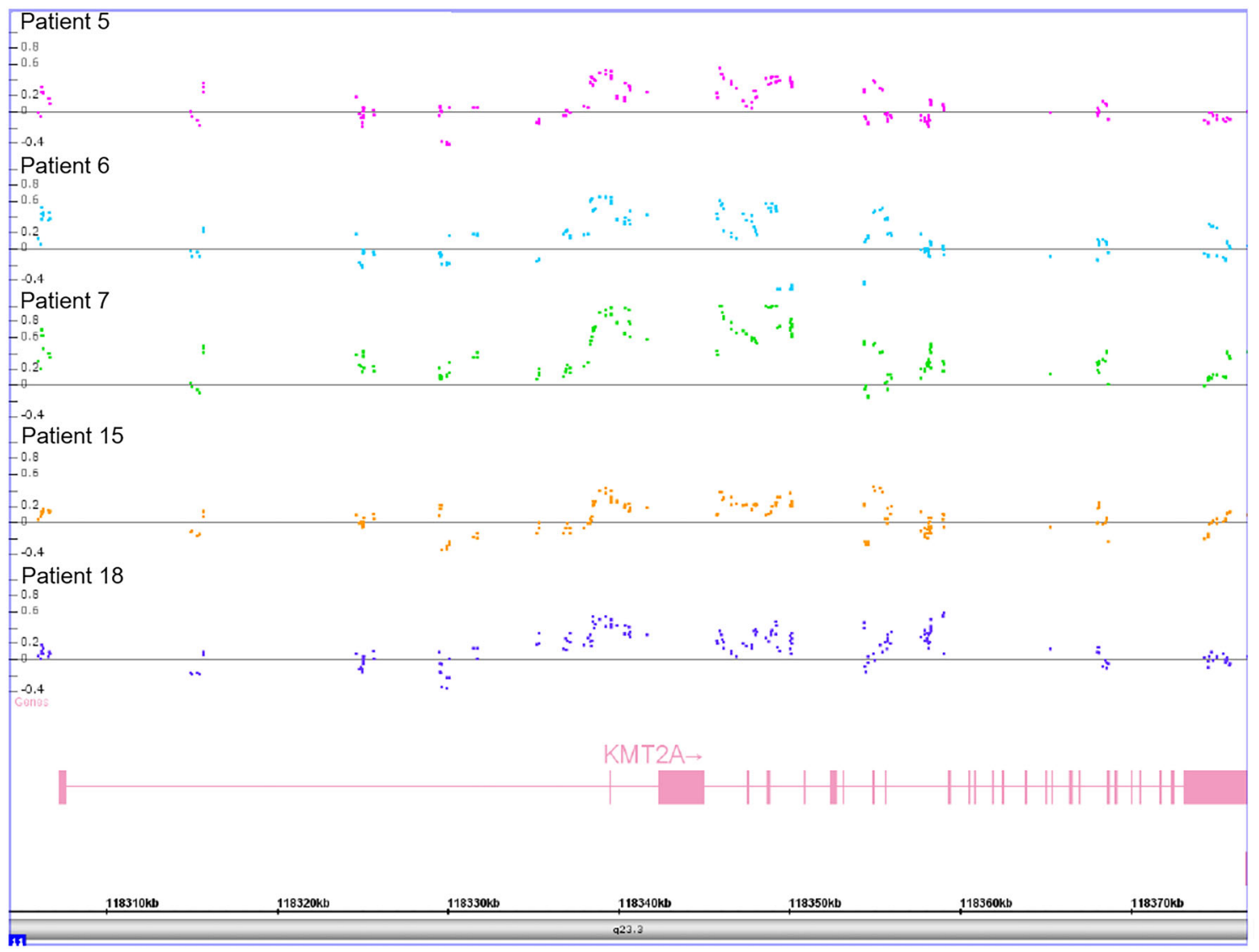

FIGURE 5 Genomic locations and graphic display of array results for KMT2A-PTD. Patient 7 had gain of 11q23.3 at the other homologue of chromosome 11. KMT2A-PTD, KMT2A partial tandem duplication [Color figure can be viewed at wileyonlinelibrary.com]

accounted for by the presence of KMT2A-PTD, the data imply that other additional abnormalities also impact the prognosis of MDS.

Although the types of abnormalities we noted in our study were largely similar to those reported in previous studies analyzing SNP-A in MDS patients, ${ }^{4-7}$ the frequency of additional SNP-A abnormalities in our study of $47 \%$ was higher than previous reports, which showed a range of $18 \%$ to $39 \%$ of cases with additional SNP-A abnormalities. The increased frequency we observed could potentially be due to higher resolution of our array platform and as well as our analysis. Coincident with this observation, KMT2A-PTD was only rarely reported in these prior studies, whereas in our study this abnormality was the most common additional SNP-A abnormality observed.

The data also demonstrate that the effect of additional SNP-A abnormalities is particularly profound in cases that have very goodintermediate karyotypic features or cases of otherwise lowintermediate risk by IPSS-R. Thus, the SNP-A may be more effectively utilized in these particular cases and, perhaps not surprisingly, is more limited in usefulness in cases that already have definitive poor risk features. Moreover, because a large proportion of cases in the very low-intermediate risk/very good-intermediate cytogenetic groups are patients with a normal karyotype, SNP-A is a potentially useful tool in further delineating risk subgroups within this substantial fraction of MDS cases. Interestingly, the survival of patients in our study was longer than those of prior studies that performed survival analysis, 5,7 which showed a median survival of 43 to 50 months in patients with favorable or normal karyotype without SNP-A abnormalities and 16 to 20 months in patients with additional SNP-A abnormalities. The relatively increased OS seen in our cohort compared to prior studies may potentially be attributed to either differences in patient population, clinical practice, or a consequence of relatively smaller cohort size.

The contribution of individual specific abnormalities to prognosis also remains an area of future investigation. Our data suggest KMT2APTD may be partially responsible for the poorer survival seen in MDS patients, who otherwise might be classified as having lower risk disease, though a definitive determination is limited by the small number of KMT2A-PTD. Additionally, two cases also identified CN-LOH as additional anomalies on chromosome arms $7 q$ and $11 q$, respectively, which contain the genes EZH2 on $7 q$ and $C B L$ on $11 q$, both recurrently mutated in MDS with suggested adverse prognostic impact. ${ }^{13-16}$ Consequently, the relative contribution of KMT2A-PTD to prognosis requires further confirmation in larger sample study. Because patients with additional SNP-A abnormalities have poorer OS and relatively increased risk, the presence of these abnormalities may potentially identify these patients as candidates for more urgent therapeutic intervention including transplantation. 
While conventional karyotype continues as expected standard practice in MDS diagnosis, the appropriate utilization of other related ancillary testing to provide a comprehensive genetic assessment is an important as-yet unresolved issue. For example, fluorescence in situ hybridization (FISH) analysis can also detect additional abnormalities outside of karyotype, ${ }^{17,18}$ however the National Comprehensive Cancer Network (NCCN) practice guidelines currently only recommend FISH in cases where standard cytogenetics cannot be obtained. ${ }^{19}$ The American Society for Clinical Pathology also supports a similar recommendation. ${ }^{20}$ The European Society for Medical Oncology (ESMO) practice guidelines slightly differ in this respect as they acknowledge a potential benefit of FISH in cytogenetically normal cases and thus recommend FISH in the setting of normal karyotype. ${ }^{21}$ A similar algorithm could potentially be applied with respect to SNP-A by focusing its utilization in cases that would otherwise be designated of lower risk. Recent studies have attempted to compare the relative detection rates of abnormalities across different modalities and have confirmed overall relatively higher resolution in SNP-A ${ }^{22}$ and next generation sequencing platforms which complement standard cytogenetics and FISH analysis. ${ }^{23}$ Outside of larger genomic alterations, the impact of point mutations, which have also been implicated in survival of MDS patients with further prognostic relevance, ${ }^{15,24}$ remains another area for subsequent investigation. As clinical standard of care does not yet include testing for point mutations, we were unable to ascertain their significance in the context of additional SNP-A abnormalities, but this is an area in which further analysis is warranted.

In conclusion, these findings demonstrate the potential prognostic and therapeutic impact of the cytogenomic array, with particular utility in MDS cases that would otherwise be classified as very lowintermediate risk.

\section{ORCID}

Sarah M. Choi (D) https://orcid.org/0000-0002-7028-7313

\section{REFERENCES}

1. Greenberg PL, Tuechler H, Schanz J, et al. Revised International Prognostic Scoring System for myelodysplastic syndromes. Blood. 2012; 120(12):2454-2465.

2. Li MM, Monzon FA, Biegel JA, et al. A multicenter, cross-platform clinical validation study of cancer cytogenomic arrays. Cancer Genet. 2015;208(11):525-536

3. Maciejewski JP, Tiu RV, O'Keefe C. Application of array-based whole genome scanning technologies as a cytogenetic tool in haematological malignancies. Br J Haematol. 2009;146(5):479-488.

4. Stevens-Kroef MJ, Olde Weghuis D, Elldrissi-Zaynoun N, et al. Genomic array as compared to karyotyping in myelodysplastic syndromes in a prospective clinical trial. Genes Chromosomes Cancer. 2017;56(7): 524-534.

5. Thiel A, Beier M, Ingenhag D, et al. Comprehensive array CGH of normal karyotype myelodysplastic syndromes reveals hidden recurrent and individual genomic copy number alterations with prognostic relevance. Leukemia. 2011;25(3):387-399.

6. Mohamedali A, Gäken J, Twine NA, et al. Prevalence and prognostic significance of allelic imbalance by single-nucleotide polymorphism analysis in low-risk myelodysplastic syndromes. Blood. 2007;110(9): 3365-3373.

7. Tiu RV, Gondek LP, O'Keefe CL, et al. Prognostic impact of SNP array karyotyping in myelodysplastic syndromes and related myeloid malignancies. Blood. 2011;117(17):4552-4560.

8. Starczynowski DT, Vercauteren S, Telenius A, et al. High-resolution whole genome tiling path array $\mathrm{CGH}$ analysis of CD34+ cells from patients with low-risk myelodysplastic syndromes reveals cryptic copy number alterations and predicts overall and leukemia-free survival. Blood. 2008;112(8):3412-3424.

9. Deeg HJ, Scott BL, Fang M, et al. Five-group cytogenetic risk classification, monosomal karyotype, and outcome after hematopoietic cell transplantation for MDS or acute leukemia evolving from MDS. Blood. 2012;120(7):1398-1408.

10. Schanz J, Tuchler H, Sole F, et al. New comprehensive cytogenetic scoring system for primary myelodysplastic syndromes (MDS) and oligoblastic acute myeloid leukemia after MDS derived from an international database merge. J Clin Oncol. 2012;30(8):820-829.

11. Wang Y, Miller S, Roulston D, Bixby D, Shao L. Genome-wide singlenucleotide polymorphism array analysis improves prognostication of acute lymphoblastic leukemia/lymphoma. J Mol Diagnostics. 2016;18 (4):595-603.

12. Choi SM, Dewar R, Burke PW, Shao L. Partial tandem duplication of KMT2A (MLL) may predict a subset of myelodysplastic syndrome with unique characteristics and poor outcome. Haematologica. 2018; 103(3):e131-e134.

13. Martin I, Such E, Navarro B, et al. Prognostic impact of gene mutations in myelodysplastic syndromes with ring sideroblasts. Blood Cancer J. 2017;7(12):630.

14. Xu L, Gu Z-H, Li Y, et al. Genomic landscape of CD34+ hematopoietic cells in myelodysplastic syndrome and gene mutation profiles as prognostic markers. Proc Nat Acad Sci U S A. 2014;111(23):85898594.

15. Bejar R, Stevenson K, Abdel-Wahab O, et al. Clinical effect of point mutations in myelodysplastic syndromes. N Engl J Med. 2011;364(26): 2496-2506.

16. Hou H-A, Tsai C-H, Lin C-C, et al. Incorporation of mutations in five genes in the revised International Prognostic Scoring System can improve risk stratification in the patients with myelodysplastic syndrome. Blood Cancer J. 2018;8(4):39.

17. Braulke F, Jung K, Schanz J, et al. Molecular cytogenetic monitoring from CD34+ peripheral blood cells in myelodysplastic syndromes: First results from a prospective multicenter German diagnostic study. Leuk Res. 2013;37(8):900-906.

18. Coleman JF, Theil KS, Tubbs RR, Cook JR. Diagnostic yield of bone marrow and peripheral blood FISH panel testing in clinically suspected myelodysplastic syndromes and/or acute myeloid leukemia: A prospective analysis of 433 cases. Am J Clin Pathol. 2011;135 (6):915-920.

19. (U.S.) NCCN. Myelodysplastic Syndrome (Version 2); 2019. https: //www.nccn.org/professionals/physician_gls/PDF/mds.pdf.

20. Pathology ASfC. 2016. http://www.choosingwisely.org/clinicianlists/american-society-clinical-pathology-fish-for-myelodyplastic-syndrome-related-abnormalities/.

21. Fenaux P, Haase D, Sanz GF, Santini V, Buske C, Group EGW. Myelodysplastic syndromes: ESMO Clinical Practice Guidelines for diagnosis, treatment and follow-up. Ann Oncol. 2014;25(Suppl 3):iii57-iii69.

22. Makishima H, Rataul M, Gondek LP, et al. FISH and SNP-A karyotyping in myelodysplastic syndromes: Improving cytogenetic detection of del(5q), monosomy 7, del(7q), trisomy 8 and del(20q). Leuk Res. 2010;34(4):447-453.

23. Mukherjee S, Sathanoori M, Ma Z, et al. Addition of chromosomal microarray and next generation sequencing to FISH and classical cytogenetics enhances genomic profiling of myeloid malignancies. Cancer Genet. 2017;216-217:128-141. 
24. Haferlach T, Nagata Y, Grossmann V, et al. Landscape of genetic lesions in 944 patients with myelodysplastic syndromes. Leukemia. 2014;28(2):241-247.

\section{SUPPORTING INFORMATION}

Additional supporting information may be found online in the Supporting Information section at the end of this article.
How to cite this article: Choi SM, Van Norman SB, Bixby DL, Shao L. Cytogenomic array detects a subset of myelodysplastic syndrome with increased risk that is invisible to conventional karyotype. Genes Chromosomes Cancer. 2019; 58:756-774. https://doi.org/10.1002/gcc.22783 